\section{Ward round practice - A need for urgent attention?}

I read with interest and surprise the paper 'A survey of ward round practice' by Hodgson et al (Psychiatric Bulletin, May 2005, 29, 171-173). This paper greatly disappointed me in that standard practice in the West Midlands indicates that ward rounds are being run for the professionals rather than for patients. I wonder how the professionals surveyed would feel if they were interviewed by the consultant psychiatrist in front of a room full of strangers at a time when they were acutely ill and vulnerable. I have vowed never to subject patients to this practice.

A brief survey of the adult mental health teams working in Aberdeen City and Aberdeenshire who admit patients to the acute wards at Royal Cornhill Hospital, Aberdeen found that none of the 15 teams carry out ward rounds in the way suggested in the paper. The teams discuss detailed care plans for the next week at the weekly team meeting involving wardbased staff. Any interviews between patients and professionals are carried out separately and in privacy as patients have consistently indicated to us that this is their preferred model for in-patient assessment.

I am also surprised by the findings that no pharmacists attend the ward rounds of 96 consultants, since I and my colleagues clearly showed the benefits of pharmaceutical input to mental health teams as long ago as 1996 (Kettle et al, 1996). Within the service for which I am responsible, pharmacy staff are regarded as core and essential members of mental health teams and in our experience make an invaluable contribution to team meetings.

KETTLE, J., DOWNIE, G., PALIN, A., et al (1996) Pharmaceutical care activities within a mental health team. Pharmaceutical Journal, 25, 814-816.

Alastair N. Palin Consultant in Adult Psychiatry, Clinical Director, Grampian Mental Health Services, Royal Cornhill Hospital, Aberdeen

\section{Wards rounds: for one or all?}

Hodgson et al (Psychiatric Bulletin, May 2005, 29, 171-173) point out that little is known about ward round practice, and White \& Karim (Psychiatric Bulletin, June $2005,29,207-209$ ) found that 46 out of 100 patients experienced anxiety in relation to ward rounds.

Some years ago in Milton Keynes we tried a communal ward round, which all available staff and all the team's inpatients (usually between six and ten) attended. After words of welcome and introducing the staff, the patients were told that if they wished to see the team on their own, they could do so at the end of the round, and could either stay until then or come back later (very few patients requested this). Then we went round the patients in turn, and their key worker would report on the week's progress, discuss medication, level of observation, leave arrangements and plans for discharge.

There were several advantages. There was saving of time, as the welcoming and introduction of staff only had to be done once. Explanations of drug actions, sideeffects and other matters, which often affected more than one patient, could be done once for all. Patients had less anxiety, because no one had to go in and confront the team alone, and no one was left wondering when, and even if, he or she would be summoned. An unexpected benefit was the sometimes powerful intervention of fellow patients, for instance if one wanted leave or was reluctant to take medication, sometimes the other patients would try to set them right, saying, for instance, 'Do you remember what happened yesterday? That shows you are not ready for leave yet'. This social pressure from peers was often more effective than advice from the team.

There were some disadvantages. New patients could not be presented in detail because of confidentiality, so they were dealt with at a separate meeting. It was not appropriate for spouses and family members to attend, and they were seen separately.

Most patients preferred the communal meeting, but this may have been because the unit was run on group lines, and, for instance, had a ward meeting every morning so the patients were accustomed to groups. In another type of setting it might have been less acceptable.

Personally I found these group ward rounds more efficient and also more enjoyable than seeing patients one by one. My regret is that we did no formal audit. Perhaps someone else might try it.

John Price Odintune Place, Plumpton BN7 3AN e-mail: johnscottprice@hotmail.com

\section{The first cohort of OSCE Part 1 candidates reaching Part 2}

In her letter (Psychiatric Bulletin, February 2005, 29, 72-73) Dr Narula asked how the candidates taking the Part 2 clinica examination in May 2005 would cope? Unlike their predecessors, the current cohort has no previous experience of doing a 'long case' in the old-style Part 1 examination.

We are a team of specialist registrars who help run the Guy's, King's and St Thomas' MRCPsych course. This, among other things, involves arranging mock clinical examinations. We observed that the candidates sitting the mock Part 2 examination in March 2005 struggled with the long case component. Candidates particularly had difficulties with their timing, often taking well over 10 min to present the case, and found it difficult to succinctly summarise the key features of the history of presenting complaint. The feedback we received from the candidates after the mock examination was that they were afraid to leave out what they perceived as important information from the history even if it meant going over time.

Given the increased specialisation of training posts and the changing working patterns owing to the European Working Time Directive, are candidates receiving less opportunity to take full histories from patients previously unknown to them? We recommend increased focus on basic skills during training, such as the ability to take concise but informative histories, which should be presented to supervisors during clinical work and in examination-focused teaching groups.

*Paul Whelan Specialist Registrar, University Hospital Lewisham, London, e-mail: paul.whelan@ slam.nhs.uk, Laurence Church Specialist Registrar, East Kent Community NHS Trust, e-mail: laurence.church@ekentmht.nhs.uk

\section{Appraisal and the European Working Time Directive}

Brown and Bhugra's article on the European Working Time Directive has drawn much needed attention to the practical solutions which are being discussed to counter the difficulties following its implementation (Psychiatric Bulletin, May 2005, 29, 161-163)

Another important consideration has to be the introduction of revalidation and appraisal. Appraisal involves discussion of a doctor's clinical practice, and planning improvements in their development as a clinician. For the time being, revalidation is undergoing a review by the Chief Medical Officer, Sir Liam Donaldson, following criticisms in the fifth report of the Shipman Inquiry (see http://www. the-shipman-inquiry.org.uk/fifthreport.asp). The review of the basic and higher training programmes provides an opportunity to introduce a process similar to appraisal during these years. An appraisal system could be based on the revised curriculum and allow an opportunity to incorporate other areas of particular interest to the trainee, all integrated in the form of a personal development plan (PDP). The College introduced PDPs in April 2001 and understanding the underlying principles at an earlier stage of one's career will, over time, allow the system to 